\title{
THE INFLUENCE OF POST BEND HEAT TREATMENT ON MATERIAL PROPERTIES AND CREEP RESISTANCE OF A PIPELINE BEND
}

\author{
${ }^{1}$ Gabriela ROŽNOVSKÁ, ${ }^{1}$ Zdeněk KUBOŇ, ${ }^{2}$ Vlastimil VODÁREK \\ ${ }^{1}$ MATERIÁLOVÝ A METALURGICKÝ VÝZKUM, Ostrava, Czech Republic, EU, \\ gabriela.roznovska@mmvyzkum.cz, zdenek.kubon@mmvyzkum.cz \\ ${ }^{2}$ VSB - Technical University of Ostrava, Czech Republic, EU, vlastimil.vodarek@vsb.cz
}

https://doi.org/10.37904/metal.2021.4157

\begin{abstract}
The temperature of the hot bending of creep resistant steels is usually performed above the transition temperature $A_{c 3}$. The steel thus undergoes a short-term austenitization followed by martensitic and/or bainitic transformation during subsequent fast cooling. Especially in the case of alloyed steels the austenitization is too short to allow dissolution of special carbides and/or nitrides, which results in the bimodal distribution of these secondary phases after bending. In order to guarantee the required material properties as well as homogeneous final microstructure after bending, it is necessary to perform the complete post bend heat treatment (PBHT) comprising of normalizing and tempering.

In order to verify the influence of omitted normalization after bending on the material properties of a pipe bend made of $0.5 \mathrm{Cr}-0.5 \mathrm{Mo}-0.3 \mathrm{~V}$ heat resistant steel, two different heat treatment modes were applied after a heat cycle simulating hot bending, the first inclusive normalizing and tempering and the second where the material was only tempered. Comprehensive analysis of mechanical properties, microstructure, substructure and creep resistance was then performed to confirm the effect of PBHT regime on material behaviour.
\end{abstract}

Keywords: $0.5 \mathrm{Cr}-0.5 \mathrm{Mo}-0.3 \mathrm{~V}$ steel, hot bending, post bend heat treatment, microstructure, stress rupture test

\section{INTRODUCTION}

During hot bending of thick pipes, the required heat is generated in the inductor and only narrow annular hot zone is formed on the pipe, which continuously moves along the length of the bend and in which the shape deformation of the pipe occurs. The width of the heated area must be limited to prevent uncontrolled deformation of the pipe outside the inductor area and, therefore, the heated part of the pipe is cooled down by spraying water immediately behind the inductor. During bending, the temperature in the bending zone is kept constant and usually above the temperature $A_{c 3}$. It means that the steel undergoes a short-term austenitization cycle, in which austenite is formed first and after rapid cooling, especially in pipes with a relatively small wall thickness made of alloyed steels, it transforms into martensite and/or bainite. Temperature of bending must be high enough to obtain good plasticity and low bending forces, but not so high to allow austenitic grain growth, since such an effect cannot be completely removed by the following heat treatment. During bending, the material undergoes extensive plastic deformation, too. There is a tensile stress on the outer fiber of the bending tube (extrados) and as a result the wall thickness decreases there. Conversely, on the inside part of the bend (intrados), the material is compressed, which leads to an increase in wall thickness [1,2]. During bending at temperatures above $A_{c 3}$, ferrite (perlite, bainite or martensite) is completely converted into austenite. However, although the temperature is sufficient for this transformation, it is generally not sufficient for complete homogenization of austenite, especially in alloyed steels. Especially in the case of heat-resistant steels, the good condition of the material in the as-received state is the most important prerequisite for meeting the expected high-temperature resistance. During hot bending above $A_{c 3}$, heat-resistant steels also transform into 
austenite, but relatively low temperature and the short time at it do not allow the complete and desirable homogenization of austenite including the dissolution of secondary phases (vanadium carbides or carbonitrides). These precipitates dissolve only partially and partially coarsen. If such a microstructure is further subjected to complete normalization and tempering, the influence of previous operations will be erased and small and dispersed particles of secondary phases are formed in the structure. However, if the pipe is not normalized after bending, but it is only tempered, the particles of the secondary phase are precipitating during tempering, but their amount will be smaller by the proportion which remains undissolved during bending and these particles will further coarsen during tempering. The result is the microstructure with a bimodal secondary phase distribution, with fine carbides dissolved and coarse ones coarsened even more during further operation at elevated temperatures. All this has a negative effect on the precipitation hardening, and thus has a significant negative effect on the creep resistance either steel either welded joints [3,4]. The external manifestation of this phenomenon should be reduced strength and hardness, but more significantly, the decrease in material properties and creep resistance will only become apparent after some time of exposure to high temperature.

In order to verify the influence of omitted normalization after bending on the material properties of a pipe bend made of $0.5 \mathrm{Cr}-0.5 \mathrm{Mo}-0.3 \mathrm{~V}$ heat resistant steel, two different heat treatment modes were applied after a heat cycle simulating hot bending, the first inclusive normalizing and tempering and the second where the material was only tempered.

\section{TESTED MATERIAL AND PROCEDURES}

The experimental material was a pipe $\varnothing 370 \times 22 \mathrm{~mm}$ that was subjected to the same heating and cooling regime as is used during hot bending. Then, the sample was divided into two identical halves; one half was heat treated by normalization $\left(980^{\circ} \mathrm{C} / 1 \mathrm{~h} /\right.$ air $)$ and tempering $\left(710^{\circ} \mathrm{C} / 2.5 \mathrm{~h} /\right.$ air $)$, the other was subjected only to tempering at $710^{\circ} \mathrm{C} / 2.5 \mathrm{~h} /$ air. After heat treatment comparative material analyses were performed on the both samples obtained, including:

- $\quad$ tensile test at room temperature,

- $\quad$ Charpy-V tests at various temperatures and determination of the transition temperature DBTT,

- measurement of hardness profile around the circumference and across the pipe wall,

- analysis of microstructure,

- analysis of substructure aimed in finding the differences between the samples in amount, size and distribution of the secondary particles,

- $\quad$ short-term stress rupture tests (up to 3,000 hours) and determination of creep rupture strength.

\section{RESULTS OF ANALYSES OF MECHANICAL PROPERTIES}

The results of the tests of mechanical properties showed full compliance with the requirements of the material standard, not only for the grade 15128.5 (normalized and tempered condition) but even for the grade 15128.9 , (quenched and tempered condition), which has up to $30 \%$ higher either short-term strength either creep resistance. There was also big difference in mechanical strength between the samples, when the pipe that was only tempered had strength about $100 \mathrm{MPa}$ higher than the pipe subjected to the complete post-bend heat treatment mode (see Table 1). From a purely formal point of view, it may thus appear that a sample subjected to only tempering after bending achieves better material properties (namely strength) than a sample after a complete post-bend heat treatment. Charpy V-notch tests were performed on test specimens with tangential orientation to the pipe and in the temperature range from $-40{ }^{\circ} \mathrm{C}$ to $+50^{\circ} \mathrm{C}$. Graphic comparison of the measured data of both samples is stated in Figure 1 in the form of temperature dependences of the absorbed impact energy. 
Table 1 Results of tensile tests

\begin{tabular}{|c|c|c|c|c|}
\hline \multirow{2}{*}{ Sample } & $\begin{array}{c}\text { Proof } \\
\text { stress }\end{array}$ & $\begin{array}{c}\text { Tensile } \\
\text { strength }\end{array}$ & Elongation & $\begin{array}{c}\text { Reduction } \\
\text { of area }\end{array}$ \\
\cline { 2 - 5 } & \multicolumn{2}{|c|}{$\mathbf{M P a})$} & \multicolumn{2}{|c|}{ (\%) } \\
\hline Full PBHT & 451 & 586 & 27.5 & 77.0 \\
\hline Tempered & 572 & 675 & 20.7 & 78.0 \\
\hline $\mathbf{1 5} \mathbf{1 2 8 . 5}$ & $\geq 365$ & $490-690$ & $\min .18$ & - \\
\hline $\mathbf{1 5} \mathbf{1 2 8 . 9}$ & $\geq 430$ & $570-740$ & $\min .17$ & - \\
\hline
\end{tabular}

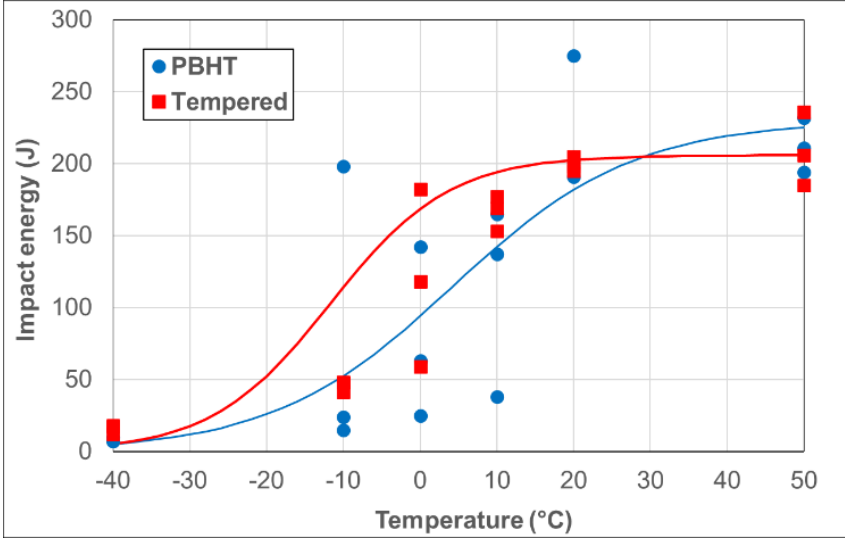

Figure 1 Vidal curve for impact energy KV

The results of the Charpy V-notch tests (Figure 1) showed a steeper slope of the impact energy for the sample that was subjected to complete PBHT, on the contrary the upper shelf is higher in the only tempered material. Also, the brittle to ductile transition temperature (DBTT) reached $-4{ }^{\circ} \mathrm{C}$ in the tempered state, while in case of completely heat-treated samples it was $+10^{\circ} \mathrm{C}$. Based on these results, the tempered material seems to have better resistance to brittle failure, too. The hardness profile of both pipe samples was measured around the circumference of the pipe and through the wall thickness and the results are shown in Figures 2 and $\mathbf{3}$. A comparison of these figures shows the significant difference in hardness between both samples, where the only tempered one has systematically higher hardness. This sample also showed a decreasing tendency of hardness from the outer to the inner pipe surface and had a large scatter of hardness results, the hardness around the circumference of this sample was within the range of 186 to $251 \mathrm{HV} 10$, while after complete PBHT the hardness ranged only from 154 to 183 HV 10.

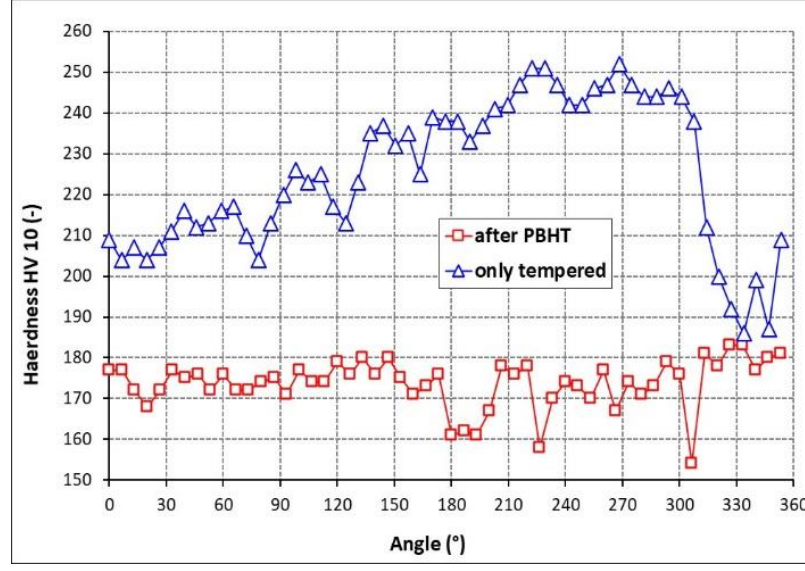

Figure 2 Hardness profile around the pipe circumference

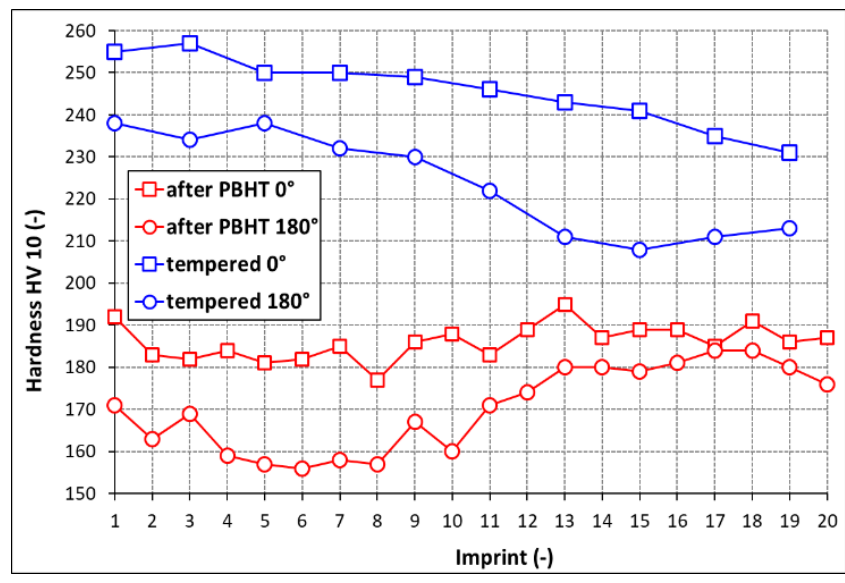

Figure 3 Hardness through the pipe wall

\section{RESULTS OF METALLOGRAPHIC AND TEM ANALYSIS OF THE STEAM PIPELINE BEND}

The microstructure of the specimen subjected to complete PBHT was heavily tempered, fine-grained and consisted of ferrite with carbides and almost spheroidized pearlite of variable size; some blocks were probably originally bainitic. Carbides were also locally precipitated along the ferritic grain boundaries, Figure 4. While the sample after complete PBHT had a microstructure of tempered, originally equiaxed grains composed of ferrite and pearlite, with a smaller proportion of bainite, the original microstructure of the sample, which was only tempered after bending, was a mixture of bainite and ferrite with the presence of numerous carbides inside the grains, Figure 5 . 


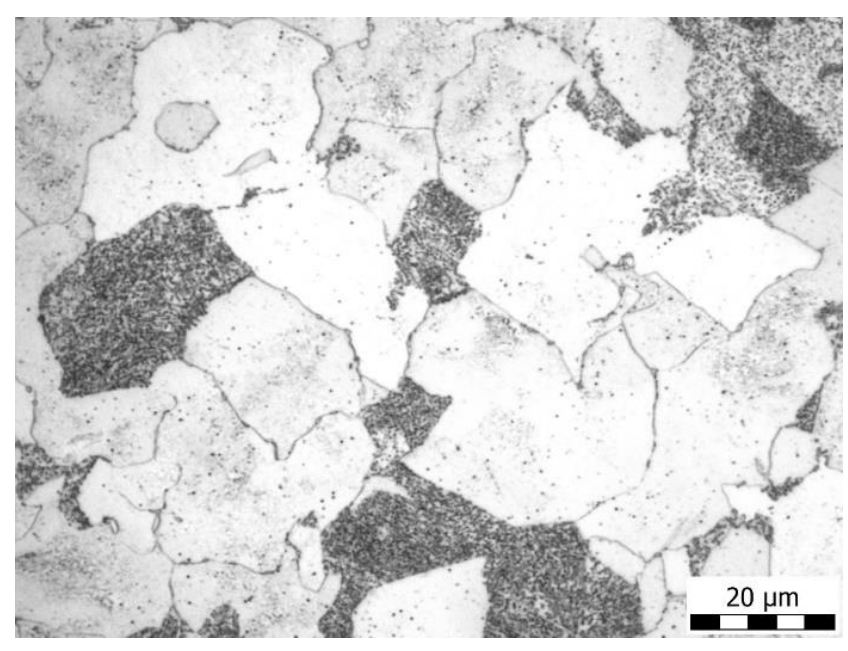

Figure 4 Microstructure of sample after compete PBHT

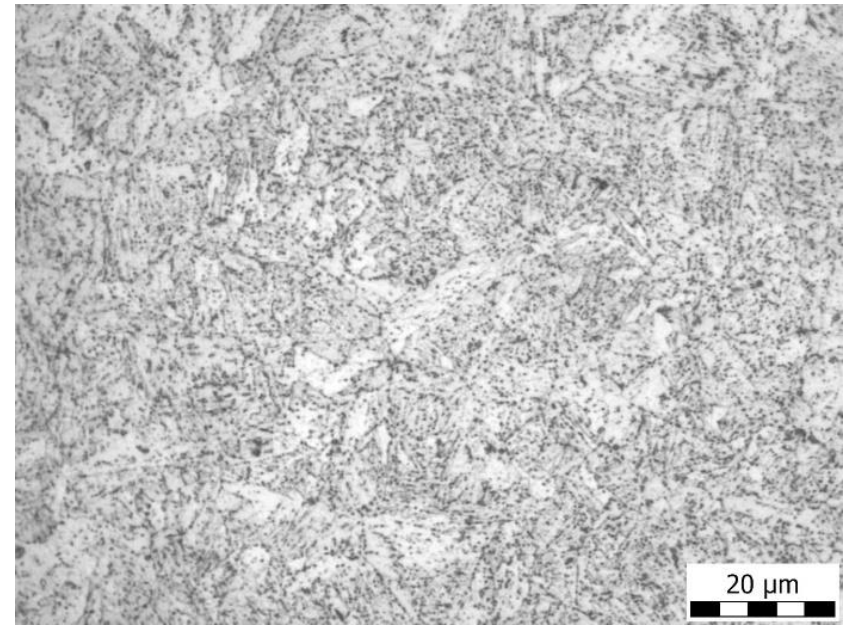

Figure 5 Microstructure of sample after tempering

The analysis of microstructure was supplemented by the analysis of the minor phases. In the sample after complete PBHT, most of the secondary particles in the ferrite precipitated intragranularly in the form of small platelets or needles; locally were also observed globular precipitates in the ferrite. While the particles in bainite were cementite and the frequency of fine MX particles was low, the globulitic particles of MX-type in ferrite were rich in titanium. The platelets and needle-like particles in ferrite were composed of MX phase, mainly rich in $\mathrm{V}$ and Mo, Figures 6 and 7.

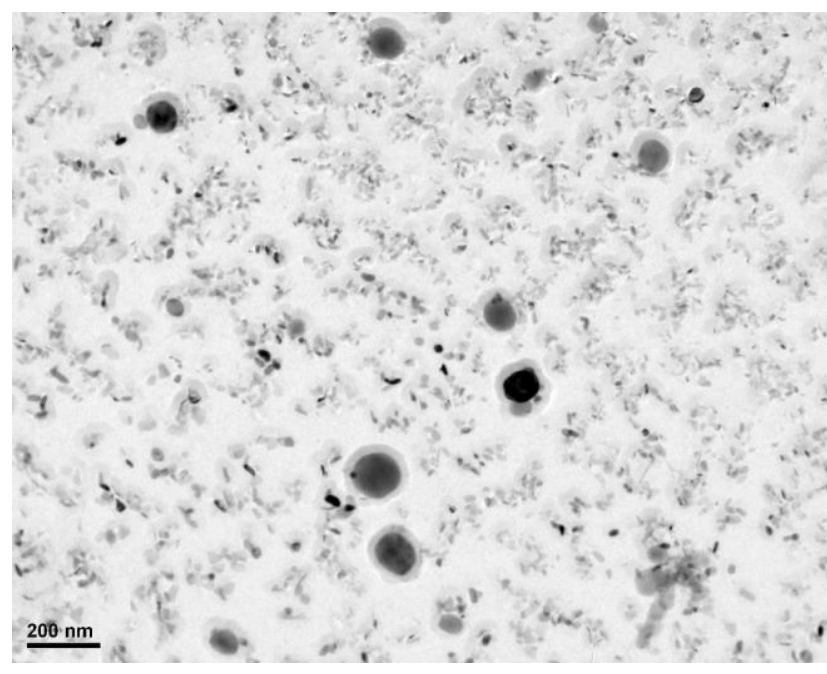

Figure 6 Secondary phases in the sample after complete PBHT

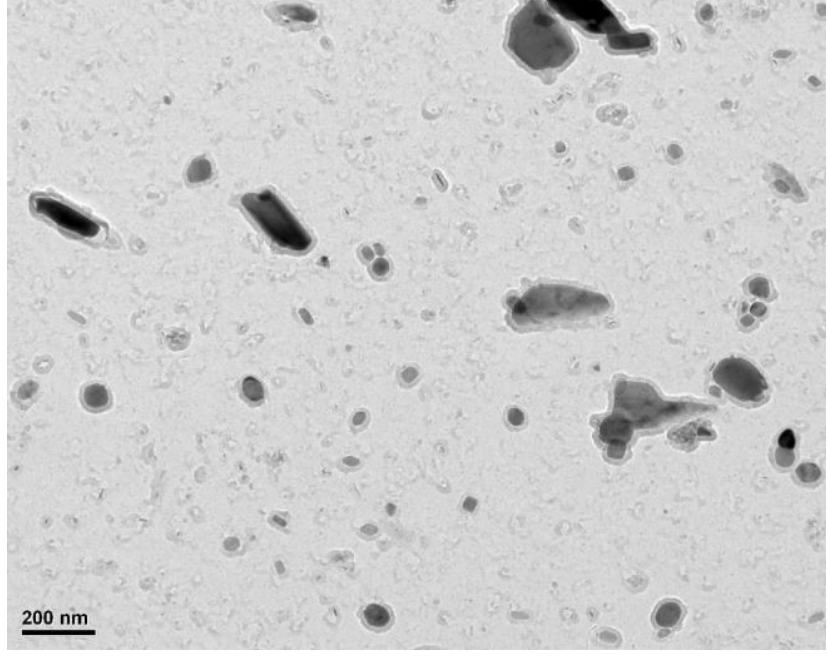

Figure 7 Secondary phases in the sample after tempering

In order to assess the effect of different post bending heat treatment of both samples on the dispersity of secondary phases in ferritic grains, image analysis of them was performed. Due to the differences in the distribution of cementite in the two samples, the results of the image analysis of sample 1 characterize mainly the MX particles, while in the case of sample 2 both $M X$ and cementite particles were analyzed. All three measured size parameters (mean particle diameter $\mathbf{D}_{\text {mean }}$, maximum particle diameter $\mathbf{D}_{\max }$ and minimum particle diameter $\mathbf{D}_{\min }$ ) are smaller in sample 1 than in sample 2, while the number of particles per unit area $\left(\mathbf{N}_{\mathbf{A}}\right)$ is higher in sample 1 (see Table 2). 
Table 2 Results of image analysis of particles of minor phases

\begin{tabular}{|c|c|c|c|c|c|}
\hline \multirow{2}{*}{ Sample } & $\mathbf{D}_{\text {mean }} \pm$ STD & $\mathbf{D}_{\max } \pm$ STD & $\mathbf{D}_{\min } \pm$ STD & $\mathbf{N}$ & $\mathbf{N}_{\mathbf{A}}$ \\
\cline { 2 - 6 } & \multicolumn{3}{|c|}{$(\mathbf{n m})$} & $\mathbf{( - )}$ & $\left(\mathbf{m m}^{-2}\right)$ \\
\hline $\mathbf{1}$ & $32.9 \pm 16.9$ & $57 \pm 30.1$ & $23.4 \pm 13.1$ & 5378 & $1.06 \cdot 10^{9}$ \\
\hline $\mathbf{2}$ & $45.7 \pm 35$ & $66.9 \pm 57.8$ & $30.9 \pm 26.8$ & 1547 & $3.05 \cdot 10^{8}$ \\
\hline
\end{tabular}

The analysis of the precipitation in both samples showed that two minor phases were present in both samples: cementite and MX phase, but the precipitation of MX particles in the ferrite of sample 1 was more intense than in sample 2, its particles were finer and more evenly distributed.

\section{RESULTS OF SHORT-TERM STRESS RUPTURE TESTS}

In addition to the above-mentioned analyses of properties, a program of short-term stress rupture tests at temperatures 550 and $575^{\circ} \mathrm{C}$ with expected times to rupture of $100,300,1,000,3,000$ and 10,000 hours was carried out on the both samples of pipe bend. The results of stress rupture tests are shown in Table 3 for sample 1 (complete PBHT) and Table 4 for sample 2 (only tempered).

Table 3 Results of stress rupture tests of sample 1

\begin{tabular}{|c|c|c|c|c|}
\hline Temperature & Stress & $\begin{array}{c}\text { Time to } \\
\text { rupture }\end{array}$ & Elongation & $\begin{array}{c}\text { Reduction } \\
\text { of area }\end{array}$ \\
\hline$\left({ }^{\circ} \mathbf{C}\right)$ & $(\mathbf{M P a})$ & $(\mathrm{h})$ & \multicolumn{2}{|c|}{$(\%)$} \\
\hline 550 & 300 & 32 & 30.8 & 83.7 \\
\hline 550 & 260 & 36 & 43.7 & 85.4 \\
\hline 550 & 210 & 302 & 37.7 & 78.2 \\
\hline 550 & 170 & 3560 & 21.5 & 55.6 \\
\hline 575 & 235 & 3 & 40.0 & 88.0 \\
\hline 575 & 200 & 38 & 45.4 & 86.9 \\
\hline 575 & 160 & 424 & 44.5 & 68.1 \\
\hline 575 & 125 & 1631 & 40.2 & 65.9 \\
\hline
\end{tabular}

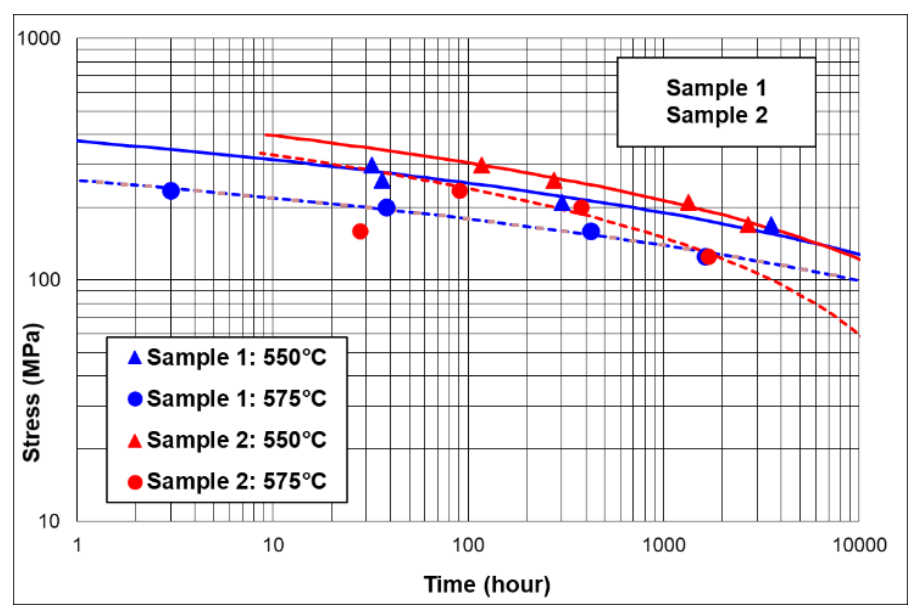

Figure 8 Comparison of stress dependence of time to rupture for both samples
Table 4 Results of stress rupture tests of sample 2

\begin{tabular}{|c|c|c|c|c|}
\hline Temperature & Stress & $\begin{array}{c}\text { Time to } \\
\text { rupture }\end{array}$ & Elongation & $\begin{array}{c}\text { Reduction } \\
\text { of area }\end{array}$ \\
\hline$\left({ }^{\circ} \mathbf{C}\right)$ & $(\mathbf{M P a})$ & (h) & \multicolumn{2}{|c|}{$(\%)$} \\
\hline 550 & 300 & 117 & 20.5 & 71.2 \\
\hline 550 & 260 & 275 & 23.8 & 73.8 \\
\hline 550 & 210 & 1334 & 18.4 & 46.0 \\
\hline 550 & 170 & 2715 & 20.3 & 51.2 \\
\hline 575 & 235 & 90 & 23.8 & 47.9 \\
\hline 575 & 200 & 378 & 21.6 & 43.3 \\
\hline 575 & 160 & 28 & 35.1 & 69.5 \\
\hline 575 & 125 & 1691 & 30.8 & 37.7 \\
\hline
\end{tabular}

For comparison of both samples, these results are shown graphically in Figure 8 in the form of stress dependence of time to rupture along with an evaluation according to the equation developed in SVÚM Praha, which is used for the mathematical and statistical treatment of stress rupture and creep test results [5]. Comparison of the calculated stress versus time to rupture for the two specimens in this figure shows first a short-term (up to about 5,000 hours) higher creep strength for sample 2 (only tempered), but then also a sharp decrease with increasing time to rupture and thus potentially worse results at long times to fracture of the material only tempered after hot bending. 


\section{DISCUSSION AND CONCLUSION}

The observed differences in the creep strength between the two samples can be put into context with the results of the analyses of mechanical properties, microstructure and especially substructure. The sample, that underwent only tempering after bending (sample 2) has higher strength and lower FATT and seems to be the preferred one. However, a detailed substructural analysis revealed that the mean particle size of the precipitates of secondary phases, which determine the creep resistance of the steels, is higher in sample 2, and at the same time the number of particles per unit area of these particles is significantly lower than in the specimen subjected to post-bend heat treatment (sample 1). It is therefore certain that the creep resistance of a specimen that has not been subjected to normalisation after bending will ultimately be adversely affected.

The explanation of the paradox, that the only tempered sample 2 achieves better results in the stress rupture tests, especially at lower temperature and short time to rupture, lies in the role of the individual strengthening mechanisms on the creep strength and especially precipitation and dislocation strengthening [6]. Precipitation strengthening is one of the most effective strengthening mechanisms in heat resistant steels. Assuming that plastic deformation occurs due to dislocation creep mechanisms, the intragranular and dispersed secondary phase particles have a decisive effect on the deformation rate. The role of dislocation strengthening during creep is different than at room temperature. While plastic deformation at room temperature results in multiplication of dislocations, shortening of their free paths, and thus increasing the strengthening, at high temperatures the effect of dislocation climbing largely eliminates this effect. The dislocations climb over the obstacle and thus disappear from a given slip plane and do not form a loop around the obstacle. The climbing of dislocations also makes their elimination significantly easier, both by mutual annihilation and at the free surface. This leads to a decrease in the effective density of dislocations and the associated dislocation strengthening. The ratio of yield stress to tensile strength in sample 2 is 0.85 (compared to 0.77 in sample 1) and it seems that fine-grained microstructure and dislocation strengthening plays a significant role in good mechanical properties of sample 2 .

\section{ACKNOWLEDGEMENTS}

This paper was created in the frame of the Institutional support for long-term and conceptual development of a research organization in 2019, provided by the Ministry of Industry and Trade of the Czech Republic.

\section{REFERENCES}

[1] MUTHMANN, E., GRIMPE, F. Fabrication of hot induction bends from LSAW large diameter pipes manufactured from TMCP plate. In: Microalloyed Steels for the Oil and Gas Industry International Symposium, Pittsburg: TMS, 2007, pp. 573-587.

[2] SHARMA, R., SHANT, R., PANDEY, B., GOYAL, R., KATHAYAT, T. Effect of Hot Induction Process on Bend Properties. Journal of Materials and Metallurgical Engineering. 2012, vol. 2, No. 2, pp. 25-32.

[3] HE, X. HU, C., WANG, Z. ZHAO, H., WEI, X., DONG, H. Carbide transformation behaviors of a Cr-Mo-V secondary hardening steel during over-ageing. Mater. Res. Express. 2020, vol. 7, No. 3, id.036511.

[4] MOHYLA, P., FOLDYNOVÁ, K. Effect of Post-Welding Heat Treatment on Mechanical Properties of Joints of Steel P92 Formed by Submerged Arc Welding. Metal Science and Heat Treatment. 2014, vol. 56, No. 3-4, pp. $206-209$.

[5] BÍNA, V., HAKL, J. Relation between creep strength and strength for specific creep strain at temperatures up to $1200^{\circ} \mathrm{C}$, Materials Science and Engineering A. 1997, vol. 234-236, pp. 583-586.

[6] KASSNER, M. E., PÉREZ-PRADO, M. T. Fundamentals of Creep in Metals and Alloys. Amsterdam: Elsevier B.V. 2004, 272 s. ISBN: 978-0-08-043637-1. 